\title{
Connecting Hunter-Schreger Band microstructure to enamel microwear features: New insights from durophagous carnivores
}

\author{
Zhijie Jack Tseng \\ Acta Palaeontologica Polonica 57 (3), 2012: 473-484 doi: http://dx.doi.org/10.4202/app.2011.0027
}

Several recent studies have clarified the link between microwear features and diet among living carnivorans, but it is still unclear whether previously interpreted evolutionary trends for dietary specialization, based on examination of enamel microstructure, are consistent with such insights from microwear analysis. This study examined the relationship between microwear and microstructure features using a sample of fossil hyaenids and canids. Hunter-Schreger Bands (HSB) and microwear features were examined at the same magnification level using optical stereomicroscopy. Multiple trials conducted on each specimen showed higher variance of smaller $(0.03 \mathrm{~mm})$ features. The number of pits was positively correlated with more derived HSB in both $\mathrm{p} 4$ and $\mathrm{m} 1$; fossil teeth with derived HSB possessed microwear features similar to patterns found in modern spotted hyenas. Microscopic scratches were not as closely associated with HSB patterns, but large scratches were more tightly linked to HSB than smaller ones on p4. An examination of evolutionary trends in HSB specialization in the two carnivoran lineages showed that derived HSB patterns evolved prior to the highly robust craniodental characteristics typical of later bone-cracking ecomorphologies. Therefore, the increase of hard food in the diet of less specialized hyaenids and canids was accompanied by a mosaic mode of evolution, with microstructural changes preceding key macrostructural morphological adaptations.

Key words: Mammalia, Borophagine, Canidae, Hyaenidae, durophagy, bone-cracking, Miocene, Cenozoic.

Zhijie Jack Tseng [jtseng@nhm.org] Integrative and Evolutionary Biology Program, Department of Biological Sciences, University of Southern California, Los Angeles, California 90089, USA and Department of Vertebrate Paleontology, Natural History Museum of Los Angeles County, 900 Exposition Boulevard, Los Angeles, California 90007, USA.

This is an open-access article distributed under the terms of the Creative Commons Attribution License (for details please see creativecommons.org), which permits unrestricted use, 
distribution, and reproduction in any medium, provided the original author and source are credited.

Faf Full text $(447.4 \mathrm{kB})$ 